\title{
Double-Virus Resistance of Transgenic Oriental Melon Conferred by Untranslatable Chimeric Construct Carrying Partial Coat Protein Genes of Two Viruses
}

\author{
Hui-Wen Wu, Department of Plant Pathology, National Chung Hsing University, Taichung, Taiwan; Tsong-Ann Yu, \\ Department of Molecular Biotechnology, Da-Yeh University, Changhua, Taiwan; and Joseph A. J. Raja, Serene \\ Judith Christopher, Sine-Lan Wang, and Shyi-Dong Yeh, Department of Plant Pathology, National Chung Hsing \\ University, Taichung, Taiwan
}

\begin{abstract}
Wu, H.-W., Yu, T.-A., Raja, J. A. J., Christopher, S. J., Wang, S.-L., and Yeh, S.-D. 2010. Double-virus resistance of transgenic oriental melon conferred by untranslatable chimeric construct carrying partial coat protein genes of two viruses. Plant Dis. 94:1341-1347.

Production of oriental melon (Cucumis melo var. makuwa) in Asia is often limited by two potyviruses, the watermelon infecting type of Papaya ringspot virus (PRSV W) and Zucchini yellow mosaic virus (ZYMV). In order to engineer transgenic resistance to these two viruses, an untranslatable chimeric DNA comprising partial coat protein $(\mathrm{CP})$ sequences of ZYMV and PRSV W was constructed and used to transform the elite cultivar of oriental melon, Silver Light, by Agrobacterium. Greenhouse evaluation by mechanical challenges with ZYMV and PRSV W, alone or together, identified transgenic lines exhibiting different levels of resistance or complete immunity to ZYMV and PRSV W. Molecular analyses of transgenic lines revealed random insertion of transgene into the host genome, with insert numbers differing among transformants. There was no correlation between transgene insert numbers and the degree of resistance expressed by transgenic lines. The levels of accumulation of transgene transcript varied among transgenic lines. However, an inverse correlation was observed between the level of accumulation of transgene transcripts and the degree of virus resistance. Moreover, small interfering (si)RNA was readily detected from the immune and highly resistant lines, but not from the weakly resistant and susceptible lines. Altogether, our results indicated that RNA-mediated posttranscriptional gene silencing (PTGS) was the underlying mechanism of double-virus resistance of the transgenic melon lines. The segregation analysis of the $R_{1}$ progeny of the immune line $\mathrm{ZW}-1$ indicated that the single inserted transgene is associated with the resistance phenotype and is inherited as a dominant trait. These transgenic melon lines with high degrees of resistance to ZYMV and PRSV W have great potential for the control of ZYMV and PRSV W in C. melo in Asia and elsewhere.
\end{abstract}

Melons (Cucumis melo L.), which originated in Africa and Southwest Asia $(40,43)$, are grown worldwide in a variety of climates. The oriental melon (Cucumis melo L. var. makuwa Makino), which has globular or flat globular fruits with green, white, or yellow peel and aromatic flavor, is widely cultivated in the Middle East, East Asia, and South Asia (31). Like other melon varieties, the oriental melon is susceptible to infection by many viruses $(5,7,8,19)$. Two aphid-borne potyviruses, Zucchini yellow mosaic virus (ZYMV) and the watermelon-infecting type of Papaya ringspot virus (PRSV W), limit melon production worldwide (36). Typical members of the genus Potyvirus, ZYMV and

Corresponding author: S.-D. Yeh

E-mail: sdyeh@nchu.edu.tw

* The $\boldsymbol{e}$-Xtra logo stands for "electronic extra" and indicates that Figures 2 and 3 appear in color in the online edition.

Accepted for publication 14 July 2010.

doi:10.1094/PDIS-11-09-0742

(C) 2010 The American Phytopathological Society
PRSV W have flexuous particles $(\sim 750 \times$ $12 \mathrm{~nm}$ ) encapsidating a monopartite single-stranded RNA genome of positive polarity $(11,25,35)$. Plants of melon varieties infected with these two viruses, alone or together, are stunted with deformed leaves displaying symptoms of severe mosaic and blistering, and produce discolored and deformed fruits lacking market value $(18,25,34)$.

Several resistance genes to potyviruses have been identified in germplasm collections of melon. For example, resistance to PRSV W is governed by a single dominant Prv gene $(32,46)$. Molecular markers linked to the ZYMV resistance Zym allele (10) and PRSV W resistance $\operatorname{Pr} v^{1}$ allele in melon (42) have been identified and used to assist in breeding programs. Although a melon breeding line is resistant to the three potyviruses ZYMV, PRSV W, and Watermelon mosaic virus (WMV), as well as to powdery mildew (2), incorporation of resistance genes into elite $C$. melo by traditional breeding has not been fully accomplished because of linkage of these resistance genes to undesirable traits. Moreover, since the complex trait of virus resistance in melon may be controlled by coordinated functioning of several genes, the consequent independent segregation makes conventional breeding a long-term and time-consuming effort (2). DaninPoleg et al. (9) presented evidence for the complementary functioning of three dominant genes in determining ZYMV resistance in melon, although the same trait earlier was determined to be the result of a single gene (33). Of the genetic engineering strategies attempted for virus control in melons, the pathogen-derived resistance (PDR) approach (38) is technically simple, functionally efficacious, and genetically stable, owing to the single-transgenecontrolled nature of the engineered trait. Hence, engineering melon with viral genes to generate virus resistance is considered a better alternative to a conventional breeding program.

Transgenic cucurbit crops with multiple virus resistance can be generated by engineering the plants with coat protein $(\mathrm{CP})$ genes from more than one virus. Multiviral $\mathrm{CP}$ transgenic cucurbits include transgenic squash resistant to Cucumber mosaic virus (CMV), WMV, and ZYMV $(13,15,44)$ and transgenic cantaloupe $(C$. melo L. var. cantalupensis) resistant to CMV, ZYMV, and WMV (14). However, the multi-viral $\mathrm{CP}$ transgenes in these cases are under the control of independent cis-acting regulatory elements. This approach confers multiple virus resistance, but it does not guarantee balanced expression of individual transgenes and their faithful co-segregation to progeny. Alternatively, the variable expression and the lack of co-segregation can be prevented by designing single-promoter-controlled chimeric transgenes possessing sequence from multiple virus genes. A singlepromoter-controlled chimeric transgene comprising the full-length $\mathrm{CP}$ sequence of Turnip mosaic virus (TuMV) and a partial $\mathrm{N}$ gene sequence of Tomato spotted wilt virus (TSWV) has been transferred to plants of Nicotiana benthamiana to generate plants resistant to both viruses (20). The efficacy of this approach in conferring effective broad-spectrum virus resistance has also been demonstrated by a composite transgene comprising segments of the $\mathrm{N}$ gene elements from four economically important tomato-infecting tospoviruses (4).

In this investigation, we constructed a single-promoter-controlled untranslatable 
chimeric construct comprised of partial $\mathrm{CP}$ genes of ZYMV and PRSV $\mathrm{W}$ and used this construct to generate transformants of an elite cultivar of oriental melon called Silver Light (Known-You Seed Co., Taiwan) using the improved Agrobacteriummediated transformation protocol developed by our laboratory (47). Greenhouse evaluation of transformants identified several promising transgenic lines with high degrees of resistance or immunity to both ZYMV and PRSV W. Molecular analyses of the transgenic lines indicated that the transgenic resistance is triggered by posttranscriptional gene silencing (PTGS) $(3,45)$. These transgenic melon lines with double-virus resistance have great potential for control of these two potyviruses which are prevalent in Asia and elsewhere.

\section{MATERIALS AND METHODS}

Construction of untranslatable chimeric construct carrying partial ZYMV and PRSV W CP genes. The part of the ZYMV genome encoding the N-terminal portion of the CP (nt 1-533) was amplified from pZYMVGFPhis-3, an infectious cDNA clone of ZYMV (24), by polymerase chain reaction (PCR) with the primers ZCP-1, 5'-ACCATGGAATAA TAAATCAGGCACTCAGCCAAC-3' (NcoI site is boldfaced and two termination codons are underlined) and ZCP-544, 3'CTCAGATGCAGCTGAGGTACCCA-5'

(KpnI site is boldfaced and a termination codon is underlined). The part of the PRSV W genome encoding the C-terminal portion of CP (nt 507-930) was amplified by PCR from pPRSV-W-CI, an infectious cDNA clone of PRSV W (6), with the primers WCP-487, 5'-ATGGTACCATC TAAAGACATATCTGGT-3' ${ }^{\prime}(K p n I$ site is boldfaced and a termination codon is underlined) and WCP-931, 3'-CTCCTGGGT ATGCGCAATTGAGAGCTCT-5' (SacI site is boldfaced and a termination codon is underlined). The amplified products ZYMV-CP(N) and PRSVW-CP(C) were cloned into PCRII-TOPO vector separately (Invitrogen, Carlsbad, CA). The ZYMV$\mathrm{CP}(\mathrm{N})$ and PRSVW-CP(C) inserts were released from PCRII-TOPO backbones by $X b a \mathrm{I}-K p n \mathrm{I}$ and SacI-KpnI digestions, respectively, and ligated together in the $\mathrm{XbaI}-\mathrm{SacI}$ restricted binary vector pBI121 (Clontech, CA) between the CaMV 35S promoter and the nos terminator to replace the GUS reading frame. This generated pBI121-ZWCP, which contained an untranslatable 993-bp chimeric construct comprising sequences encoding the $\mathrm{N}$ terminal portion (nt 1-533) of ZYMV CP and the C-terminal portion (nt 507-930) of PRSV W CP, both possessing engineered translation termination codons, driven by a $35 \mathrm{~S}$ promoter and terminated by a nos terminator (Fig. 1). Agrobacterium tumefaciens LBA4404 was transformed with pBI121-ZWCP by electroporation (Gene Pluser, Bio-Rad Laboratories, Hercules, CA), as described by Mattanovich et al. (26), yielding LB4404-pBI21-ZWCP for melon transformation.

Transformation and regeneration. Manually peeled seeds of $C$. melo var. makuwa cv. Silver Light (Known-You Seed Co.) were surface-sterilized in $1 \%$ commercial bleach for 5 min with gentle shaking and rinsed thoroughly with sterile water. As described earlier (47), the proximal $1-\mathrm{mm}$ portion of the elliptical cotyledon was removed, and the remaining portion was split longitudinally and transversely to yield eight pieces of explants. Transformation of the prepared explants and regeneration of plantlets followed the procedure of improved cotyledon-cutting method described previously (47).

A 20- $\mu$ l suspension of an overnight culture of A. tumefaciens LBA4404-pBI121ZWCP was added to $10 \mathrm{ml}$ of MS liquid medium (27) in individual petri plates

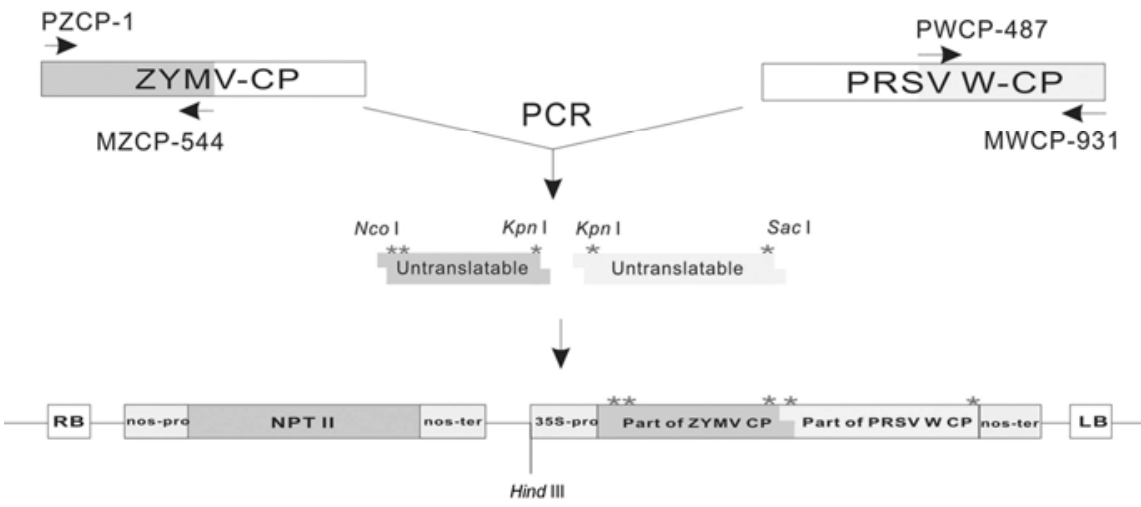

Fig. 1. Schematic presentation of the construction of an untranslatable chimeric construct comprising parts of the coat protein (CP) coding sequences of Zucchini yellow mosaic virus (ZYMV) and Papaya ringspot virus type $\mathrm{W}$ (PRSV W). The 5' portion of the chimeric transgene containing ZYMV CP fragment (nt 1-533) amplified by the primer ZCP-1 (with NcoI site and 2 stop codons) and ZCP-544 (with $\mathrm{KpnI}$ site and a stop codon). The $3^{\prime}$ portion of the chimeric transgene containing PRSV W CP fragment (nt 507-930) amplified by the primer WCP-487 (with KpnI site and a stop codon) and MWCP-931 (with SacI site and a stop codon). Ligated chimeric construct containing parts of ZYMV$\mathrm{CP}$ and PRSV W CP coding sequences was inserted into pBI121 binary vector between $35 \mathrm{~S}$ promoter and nos terminator. carrying the aforementioned explants, and the plates were incubated at room temperature for $10 \mathrm{~min}$. The infected explants were incubated in the co-culture medium for 2 days in a growth chamber at 25 to $27^{\circ} \mathrm{C}$ with a 16-h photoperiod $\left(53 \mu \mathrm{E} \mathrm{m} \mathrm{m}^{-2} \mathrm{~s}^{-1}\right.$ photon irradiance). Subsequently, the infected explants which swelled and turned green were transferred to the selection medium (47) and incubated for a period of 2 to 4 weeks. The explants that developed shoot-buds were transferred to the elongation medium (47) and allowed to develop for 2 weeks. Selected individual shoots were micropropagated on the elongation medium to generate multiple shoots which were transferred to the rooting medium (47). After 1 week, the rooted plantlets were transferred to vermiculite in plastic bags and maintained in a growth chamber at 25 to $27^{\circ} \mathrm{C}$ under a $16-\mathrm{h}$ photoperiod $(53$ $\mu \mathrm{E} \mathrm{m} \mathrm{m}^{-2} \mathrm{~s}^{-1}$ photon irradiance). After acclimatization for 2 weeks in a growth chamber, the plantlets were transferred to a temperature-controlled ( 23 to $28^{\circ} \mathrm{C}$ ) greenhouse.

The clonal individuals derived from shoot segments excised from each primary shoot were defined collectively as an $\mathrm{R}_{0}$ transgenic line.

PCR detection of transgenes. Genomic DNA was extracted from the leaves of the transgenic and nontransgenic melon plants, as described previously (16). The RNase A-treated DNAs of the putative transgenic lines were subjected to PCR with the primers ZCP-1 (forward) and WCP-931 (reverse) using the following thermal profile: 30 cycles of denaturation at $94^{\circ} \mathrm{C}$ for $2 \mathrm{~min}$, annealing at $58^{\circ} \mathrm{C}$ for $2 \mathrm{~min}$, and extension at $72^{\circ} \mathrm{C}$ for $3 \mathrm{~min}$, followed by a final extension at $72^{\circ} \mathrm{C}$ for $5 \mathrm{~min}$. Additionally, the $n p t$ II-specific primers NA ( $5^{\prime}$ CCCCTCGGTATCCAATTAGAG-3') and NB (5'-CTGGAGTTCTTCGCCA-3') were also used for PCR to ascertain the presence of the selection marker gene. The amplified products were analyzed on $0.8 \%$ agarose gels.

Evaluation of resistance of transgenic lines. The virus inocula were prepared from ZYMV-infected zucchini squash (Cucurbita pepo L.) and PRSV W-infected horn melon (Cucumis metuliferus (Naud.) Mey. [Acc. 2459]) 7 days after mechanical inoculation, with $1 \mathrm{~g}$ of leaf tissue ground and diluted to $50 \mathrm{ml}$ with $0.01 \mathrm{M}$ sodium phosphate buffer, $\mathrm{pH}$ 7.0. The inocula were mechanically introduced to Carborundum (600 mesh)-dusted second and third youngest leaves of the test plants. The $\mathrm{R}_{0}$ plants of 25 transgenic melon lines were evaluated by mechanical inoculation with ZYMV and PRSV W, alone or together (1:1 mixture of inocula). At least five $\mathrm{R}_{0}$ plants from each line were used for each inoculation with three independent replicates. The inoculated plants were kept in a temperature-controlled greenhouse $\left(23\right.$ to $28^{\circ} \mathrm{C}$ ) and observed for symptom development for 35 days. 
Indirect enzyme-linked immunosorbent assay (ELISA). Indirect ELISA for the presence of ZYMV and/or PRSV W in the virus-inoculated plants was performed as described (49). Extracts prepared from four leaf disks $(0.5 \mathrm{~cm}$ diameter) punched from different upper leaves of the plants 35 days postinoculation (dpi) were analyzed using a 5,000-fold dilution of the antiserum to ZYMV CP (23) or PRSV CP (49). A 5,000-fold diluted alkaline phosphatase (AP)-conjugated goat anti-rabbit IgG (Jackson ImmunoResearch Laboratories, West Grove, PA) was employed as the secondary antibody to detect anti-ZYMV and anti-PRSV rabbit antibodies. The absorbance at $405 \mathrm{~nm}$ was recorded (ELx800 universal microplate reader, Bio-Tek Instrument, Winooski, VT) 10 to $30 \mathrm{~min}$ after the addition of AP substrate (SigmaAldrich Fine Chemicals, Milwaukee, WI).

Southern hybridization analysis. Genomic DNA from the leaves of the transgenic and nontransgenic melon plants was extracted as described previously (16). After HindIII-digestion, the genomic DNAs were resolved (10 $\mu \mathrm{g}$ DNA/lane) on a $0.8 \%$ agarose gel and transferred to a Gene Screen Plus nylon membrane (Dupont Co., Boston, MA) with a PosiBlot 3030 Pressure Blotter and Pressure control station (Stratagene, LaJolla, CA). After UV cross-linking, the transferred DNAs were hybridized (37) with the $\left[\alpha-{ }^{32} \mathrm{P}\right]$ dATP-labeled probe prepared from the DNA fragment (0.9 kb, 25-ng) amplified from $\mathrm{pBI} 121-Z W C P$ by PCR with the primers ZCP-1 and WCP-931, using Primer-It II random primer labeling kit (Stratagene) following the manufacturer's instructions. After posthybridization washing of the filter (37), autoradiography was performed by exposing X-ray film (Hyperfilm Mp, Amersham Phamacia Biotech, UK) to the membrane at room temperature.

Detection of transgene transcript and small interfering (si)RNA by northern hybridization. For detection of the transgene transcript, total RNA was isolated from leaves of transgenic and nontransgenic plants using the (ULTRASPEC RNA isolation system (Biotecx Laboratories, Houston, TX). Aliquots of RNA (15 $\mu \mathrm{g}$ RNA/lane) were resolved on a $1.2 \%$ agarose gel with $0.9 \%$ formaldehyde and were then transferred to a nylon membrane (Dupont Co., Boston, MA) using Trans-Blot SD Semi-Dry Electrophoretic Transfer Cell (Bio-Rad). For detection of the siRNA, hybridization of total RNA was performed as described previously $(28,50)$. After the UV-crosslinking of RNA to the membrane, hybridization (37) was carried out using a radiolabeled $\mathrm{ZW}-\mathrm{CP}$ probe prepared as described above. After posthybridization washing of the membrane (37), hybridization signals were detected by autoradiography as described above. The RNA Decade Markers (Ambion Inc., Austin, TX) derived from cleavage product of a single $150 \mathrm{nt}$ gel-purified RNA transcript were $5^{\prime}$ end-labeled with $\left[\gamma-{ }^{32} \mathrm{P}\right]$ ATP by polynucleotide kinase according to the manufacture's instruction to generate markers ranging from 10 to $150 \mathrm{nt}$.

Segregation analyses of transgene. The $R_{1}$ seedlings were germinated from seeds of self-pollinated $\mathrm{R}_{0}$ plants of the immune line $\mathrm{ZW}-1$. The presence of the $\mathrm{ZW}-\mathrm{CP}$ chimeric construct in individuals was examined by PCR with ZW-CP specific primers (ZCP-1 and WCP-931) and $n p t$ II-specific primers (NA and NB) as described above. The functional nature of the inherited transgene was analyzed by mixed inoculation of the PCR-assayed $\mathrm{R}_{1}$ individuals with ZYMV and PRSV $\mathrm{W}$, and symptom development was recorded as described above.

\section{RESULTS}

Regeneration of transgenic melon lines. Cotyledon explants treated with $A$. tumifaciens LBA4404 without the chimeric CP construct became pale and declined on the selection medium within 2 weeks after transformation (Fig. 2A). In contrast, the transformed explants that survived on the selection medium (Fig. 2B) generated shootlets within 2 weeks (Fig. 2C). The explants with shootlets were transferred to the elongation medium and incubated further for 2 weeks (Fig. 2D). Elongated shoots were then excised and micropropagated on the elongation medium to form multiple shoots until they developed roots. After acclimatization in a temperature-controlled growth chamber, the plantlets were transferred to the greenhouse (23 to $28^{\circ} \mathrm{C}$ ) (Fig. $2 \mathrm{E}$ and F). The clonal plantlets rooted from shoot segments were defined as plantlets of an individual $\mathrm{R}_{0}$ line and forwarded for further assays.
Evaluation of transgenic lines under greenhouse conditions. All micropropagated $\mathrm{R}_{0}$ plants ( 5 to 15 plants in each line) of the established 25 putative transgenic lines appeared morphologically normal. The clonal plants of these lines were tested for their resistance to virus infection by mechanical inoculation with ZYMV and PRSV W, alone or together. During the observation period of $35 \mathrm{dpi}$, the $\mathrm{R}_{0}$ plants of transgenic lines exhibited different levels of resistance, which were recorded as percent individuals showing symptoms in each inoculated transgenic line (Table 1). Based on symptom development, the transgenic melon lines were graded into five categories: Susceptible (S), 16 lines, all virus-inoculated $\mathrm{R}_{0}$ individuals of these lines showed symptom development similar to nontransgenic plants; Weakly Resistant (WR), 2 lines, 51 to $84 \%$ of tested $\mathrm{R}_{0}$ plants of the indicated lines showed symptoms at $35 \mathrm{dpi}$; Moderately Resistant (MR), 2 lines, 26 to $50 \%$ of individuals showing symptoms 35 dpi; Highly Resistant (HR), 2 lines, 1 to $25 \%$ of individuals showing symptoms $35 \mathrm{dpi}$; and Immune (I), 1 line, no individual showing symptom development during the entire test period (Table 1). Although some infected individuals of different categories of transgenic lines (WR, MR, and HR) showed delayed symptoms at different times after inoculation, their symptoms progressed to the severe type similar to those of the control within 2 weeks of the onset of symptoms.

Among the transgenic lines evaluated, several were resistant, and a particular line, ZW-1 (Fig. 3A), was immune to both ZYMV and PRSV W, while the plants of certain transgenic lines, including ZW-23 (Fig. 3A), were susceptible to both viruses, similar to nontransgenic plants. Similar to

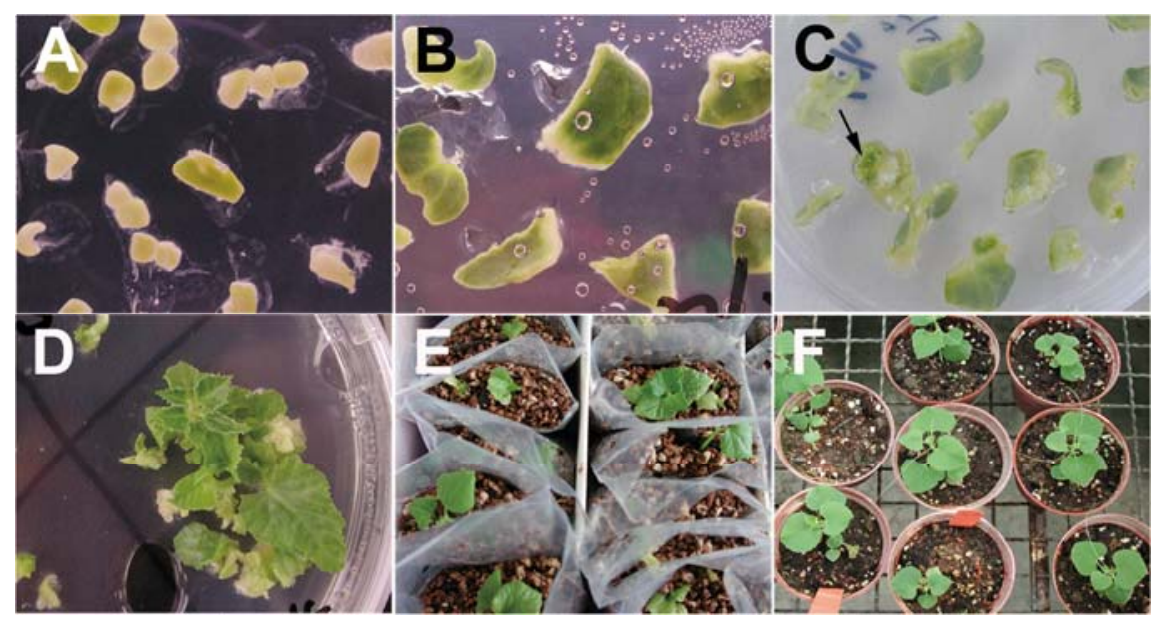

Fig. 2. Transformation of melon by the method of improved cotyledon cutting and regeneration of transgenic melon lines. A and B, Cotyledon explants treated with Agrobacterium tumefaciens LBA4404 without and with the chimeric construct on the selection medium containing $100 \mathrm{mg} / \mathrm{liter}$ of kanamycin 14 days after co-cultivation, respectively. $\mathbf{C}$ and D, Transgenic shoots emerging from cotyledon explants on the selection medium 2 to 4 weeks after transformation. $\mathbf{E}$ and $\mathbf{F}, \mathrm{R}_{0}$ plants of transgenic melon lines acclimatized in vermiculite medium with plastic bags in a growth chamber and finally established in a temperature-controlled $\left(23\right.$ to $\left.28^{\circ} \mathrm{C}\right)$ greenhouse. 
the mock-inoculated ones, the plants of transgenic line $\mathrm{ZW}-1$, after inoculation with PRSV W and ZYMV, did not show period of observation. On the contrary, as early as 4 to 5 days after inoculation, the ZYMV-inoculated nontransgenic plants showed vein-clearing and subsequent yellow-mosaic on newly emerging leaves (Fig. 3B, II). Similarly, 7 to 10 days after inoculation, the PRSV W-inoculated nontransgenic plants showed mottling and chlorotic symptoms on leaves (Fig. 3B, III). The nontransgenic plants inoculated with both viruses simultaneously exhibited symptoms more severe than those inoculated with only ZYMV or PRSV W (Fig. 3B, IV).

Detection of viruses in transgenic lines. After challenge inoculations, individual $R_{0}$ plants of each line were further assayed by ELISA using polyclonal antibodies to ZYMV CP or PRSV W CP to check for the presence of virus 2 and 4 weeks after inoculation. The results revealed that the level of accumulation of virus in the plants was inversely correlated with the degree of resistance (symptom expression) of the individual lines. Figure $3 \mathrm{C}$ shows the data obtained for the $\mathrm{R}_{0}$ plants of the susceptible line ZW-23 and the immune line ZW-1. Neither virus was detected in any of the plants of the immune line ZW-1 throughout the test period of 35 any symptoms (Fig. 3B, I) throughout the

days, indicating complete inhibition of virus accumulation in this line. In contrast, nontransgenic plants and the individuals of the susceptible line ZW-23 supported high levels of accumulation of ZYMV and PRSV W CP (Fig. 3C).

Integration of chimeric transgene. All putative transgenic melon lines yielded the expected $0.9-\mathrm{kb}$ product with the transgene-specific primer pair, indicating integration of the chimeric construct (data not presented). The PCR amplification of a $1.0-\mathrm{kb}$ product by $n p t$ II-specific primers provided independent corroboration of integration of the transgene (data not presented).

Southern hybridization analysis of transgenic lines with the radiolabeled probe confirmed the integration of the ZYMV-PRSV W CP chimeric transgene in the genome of transgenic lines (Fig. 4) of all five resistance categories (Table 1). However, the hybridization profiles of the HindIII-digested genomic DNA from the analyzed transgenic lines revealed bands of different sizes, indicating insertion of the chimeric transgene at different genomic positions in the different lines. The insert numbers of the transgene incorporated in different transgenic lines ranged from one to three (Fig. 4).

Expression of transgene transcript and accumulation of siRNA. Expression levels of transgene transcripts in transgenic

Table 1. Evaluation for virus resistance of transgenic melon lines carrying the chimeric construct comprising partial coat protein (CP) sequences of Zucchini yellow mosaic virus (ZYMV) and a watermelon-infecting type of Papaya ringspot virus (PRSV W)

\begin{tabular}{|c|c|c|c|c|c|c|}
\hline \multirow[b]{2}{*}{ Line } & \multirow[b]{2}{*}{$\begin{array}{l}\mathbf{R}_{0} \text { plants } \\
\text { assayed }\end{array}$} & \multicolumn{3}{|c|}{$\begin{array}{l}\text { Plants showing symptoms/ } \\
\text { plants reduced at } 35 \mathrm{dpi}^{\mathrm{a}}\end{array}$} & \multirow[b]{2}{*}{$\begin{array}{l}\text { Infection } \\
\text { rate }(\%)\end{array}$} & \multirow[b]{2}{*}{$\begin{array}{l}\text { Resistance } \\
\text { level }^{b}\end{array}$} \\
\hline & & ZYMV & PRSV W & $\begin{array}{l}\text { ZYMV + } \\
\text { PRSV W }\end{array}$ & & \\
\hline NT & 45 & $15 / 15$ & $15 / 15$ & $15 / 15$ & 100 & $\ldots$ \\
\hline ZW-2 & 5 & $5 / 5$ & $\ldots$ & $\ldots$ & 100 & $\mathrm{~S}$ \\
\hline ZW-3 & 5 & $5 / 5$ & $\ldots$ & $\ldots$ & 100 & $\mathrm{~S}$ \\
\hline ZW-4 & 5 & $5 / 5$ & $\ldots$ & $\ldots$ & 100 & $\mathrm{~S}$ \\
\hline ZW-5 & 5 & $5 / 5$ & $\ldots$ & $\ldots$ & 100 & $\mathrm{~S}$ \\
\hline ZW-14 & 5 & $5 / 5$ & $\ldots$ & $\ldots$ & 100 & $\mathrm{~S}$ \\
\hline ZW-15 & 5 & $5 / 5$ & $\ldots$ & $\ldots$ & 100 & $\mathrm{~S}$ \\
\hline ZW-16 & 5 & $5 / 5$ & $\ldots$ & $\ldots$ & 100 & $\mathrm{~S}$ \\
\hline ZW-17 & 5 & $5 / 5$ & $\ldots$ & $\ldots$ & 100 & $\mathrm{~S}$ \\
\hline ZW-18 & 5 & $5 / 5$ & $\ldots$ & $\ldots$ & 100 & $\mathrm{~S}$ \\
\hline ZW-19 & 5 & $5 / 5$ & $\ldots$ & $\ldots$ & 100 & $\mathrm{~S}$ \\
\hline ZW-20 & 5 & $5 / 5$ & $\ldots$ & $\ldots$ & 100 & $\mathrm{~S}$ \\
\hline ZW-21 & 5 & $5 / 5$ & $\ldots$ & $\ldots$ & 100 & $\mathrm{~S}$ \\
\hline ZW-22 & 5 & $5 / 5$ & $\ldots$ & $\ldots$ & 100 & $\mathrm{~S}$ \\
\hline ZW-23 & 5 & $5 / 5$ & $\ldots$ & $\ldots$ & 100 & $\mathrm{~S}$ \\
\hline ZW-24 & 5 & $5 / 5$ & $\ldots$ & $\ldots$ & 100 & $\mathrm{~S}$ \\
\hline ZW-25 & 5 & $5 / 5$ & $\ldots$ & $\ldots$ & 100 & $\mathrm{~S}$ \\
\hline ZW-13 & 45 & $12 / 15$ & $13 / 15$ & $13 / 15$ & 84 & WR \\
\hline ZW-12 & 45 & $12 / 15$ & $9 / 15$ & $9 / 15$ & 66 & WR \\
\hline ZW-7 & 45 & $7 / 15$ & $8 / 15$ & $7 / 15$ & 49 & MR \\
\hline ZW-11 & 45 & $6 / 15$ & $2 / 15$ & $6 / 15$ & 31 & MR \\
\hline ZW-9 & 45 & $2 / 15$ & $2 / 15$ & $3 / 15$ & 16 & HR \\
\hline ZW-8 & 45 & $0 / 15$ & $0 / 15$ & $1 / 15$ & 2 & HR \\
\hline ZW-1 & 45 & $0 / 15$ & $0 / 15$ & $0 / 15$ & 0 & I \\
\hline
\end{tabular}

a Days postinoculation.

b $\mathrm{S}$ (susceptible), no inoculated $\mathrm{R}_{0}$ individual showed a significant delay in symptom development compared to nontransgenic plants; WR (weakly resistant), 51-84\% individuals showing symptoms; MR (moderately resistant), 26-50\% individuals showing symptoms; HR (highly resistant), 1-25\% individuals showing symptoms; and I (immune), no individual showing symptoms throughout the test period. lines of different resistant categories were analyzed by northern hybridization. High levels of transgene transcript were detected from the susceptible (ZW-5, 20, and 23) and weakly resistant (ZW-12 and 13) transgenic lines, while lower levels of the transgene transcript were detected from the moderately resistant lines (ZW-7 and 11). The radioactive probe did not detect significant signals from the highly resistant lines and immune lines (ZW-8 and 9, and ZW-1, respectively) (Fig. 5A).

When the presence of siRNA was analyzed by the probes specific to the chimeric construct, an accumulation of high levels of siRNA was observed in highly resistant (ZW-8 and 9) and immune (ZW1) lines, but not in weakly resistant (ZW12 and 13) and susceptible (ZW-20 and 23) transgenic lines, as shown in Figure $5 B$. In addition, the $R_{1}$ progeny of immune line ZW-1 also showed accumulation of high levels of siRNA, indicating that the siRNA accumulation was nuclearly inherited.

Segregation and inheritance of transgenes. A total of $72 R_{1}$ seedlings derived from the immune line $\mathrm{ZW}-1$ were analyzed by PCR with transgene-specific primer pairs. Fifty-two were PCR-positive, showing a 3:1 segregation of the transgene $\left(X^{2}=\right.$ $0.29 ; P a=0.59$; the chi-square value was derived from the hypothesis of a 3:1 segregation ratio of the transgene and the probability of goodness-of-fit set at a significance level of 0.05). When the npt IIspecific primers were used, all 52 seedlings with the transgene were positive, while the other 20 seedlings without the transgene were negative, indicating a complete linkage of the selection marker gene and the chimeric CP transgene. When the $72 R_{1}$ seedlings were inoculated with ZYMV and PRSV W, none of the 52 plants with the transgene exhibited symptoms during the test period of 35 days, and all of the 20 seedlings without the transgene displayed severe symptoms of mixed infection within 10 days after inoculation. The presence of ZYMV and PRSV $\mathrm{W}$ in infected plants was confirmed by ELISA.

\section{DISCUSSION}

The genetic complexity of virus resistance and the cost, labor, and time constraints associated with the conventional breeding of melon are limitations that justified the use of genetic engineering for virus resistance (17). In the present investigation, unlike the earlier transgenic studies for squash and cantaloupe, which employed independently regulated viral coat protein transgenes (13-15), we constructed a single-promoter-controlled chimeric construct comprising untranslatable parts of the CP genes of ZYMV and PRSV W. We employed this chimeric construct for Agrobacterium-mediated transformation of the elite oriental melon cultivar Silver Light. The present study generated several 
melon lines highly resistant and immune to ZYMV and PRSV W which exhibited normal morphology, growth, and development, and produced normal fruits and viable seeds. The immune line $\mathrm{ZW}-1$ contained a single insert of the chimeric construct expressed as a single dominant locus with a simple $3: 1$ pattern of inheritance in the $\mathrm{R}_{1}$ progeny. The siRNA accumulation in $R_{1}$ progeny and the results of segregation analysis of the transgene indicated that the siRNA-induced resistance was stable and nuclearly inherited.

Our ZYMV-PRSV W CP chimeric construct can be used for engineering other cucurbits, such as watermelon, squash, cucumber, and gourd for ZYMV-PRSV W double resistance. Early reports based on protein-mediated resistance were demonstrated using a translatable transgene in viral CP-transformed cucurbits $(12,14)$. In the transformation of the watermelon rootstock Citrullus lanatus (Twinser) cultivar Gongdae with the CP gene of Cucumber green mottle mosaic virus (CGMMV) (30), the transgene transcript and its translated product were observed in a set of CGMMV-resistant lines, while in others the transcript and translation product were not detected. In that case, there was no correlation between resistance and transcript levels of the transgene or the translation product (30). RNA-mediated resistance was observed in squash transformed with the $\mathrm{CP}$ genes of Squash mosaic virus (SqMV) $(20,29)$ and cantaloupe with the CP gene of PRSV W (22). In our earlier transformation of oriental melon with ZYMV CP gene (47), although transgenic $\mathrm{CP}$ was detectable in a few transgenic lines, they were not resistant to ZYMV. However, the other transgenic lines, in which the transgene transcript was not detectable, showed high degrees of resistance or immunity to ZYMV, suggesting RNA-mediated resistance by a PTGS mechanism (47).

In the present study, in order to generate effective RNA-mediated resistance against ZYMV and PRSV W, the chimeric ZYMVPRSV W CP transgene was designed with translation termination codons to preclude the possibility of the translation of transgene transcripts. As expected, effective RNA-mediated resistance against both the viruses was observed for three transgenic lines. Northern hybridization analysis detected high levels of the chimeric transgene transcript in the susceptible, weakly resistant, and moderately resistant lines, while no transcripts were detected in the highly resistant and immune lines. A negative correlation between the level of transgene transcript and the degree of resistance of the transgenic lines indicated that the resistance mechanism is due to RNAmediated PTGS (45). In addition, accumulation of high levels of $\mathrm{CP}$ siRNA was observed in the highly resistant and immune lines, which is further evidence that the transgenic resistance is derived from siRNA-induced silencing (41).

Our results showed that individuals within each category of resistant lines (weakly, moderately, or highly resistant) did not display uniform degrees of resistance, as reflected by a subset of clonal plants micropropagated from a single shootlet developed from an explant showing different levels of symptoms, in contrast to the uniform resistance of the ZW-1 immune line individuals (Table 1). The individual differences in a particular line might have resulted from different inocu-

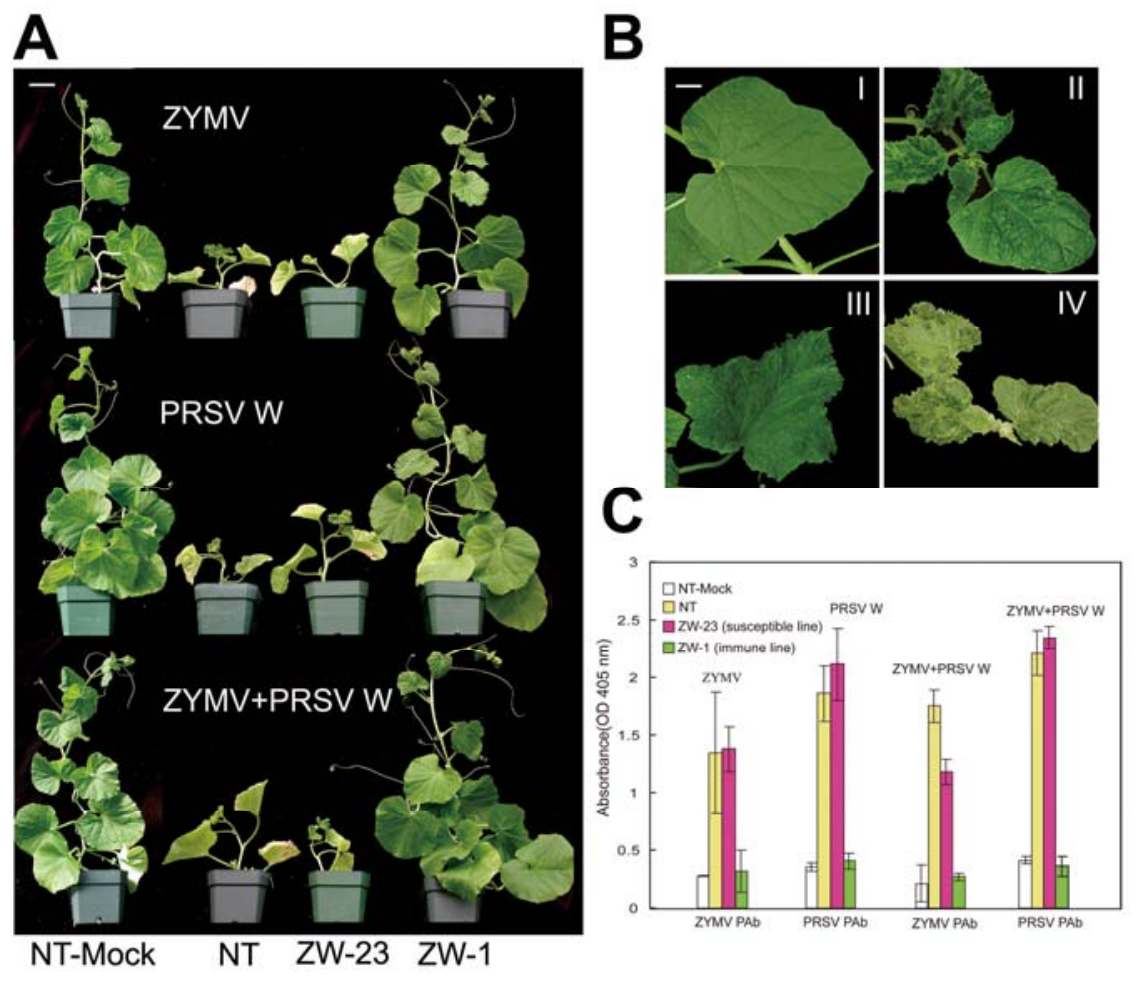

Fig. 3. Evaluation for virus resistance of transgenic $\mathrm{R}_{0}$ melon lines carrying an untranslatable chimeric construct comprised of partial coat protein (CP) coding sequences of Zucchini yellow mosaic virus (ZYMV) and Papaya ringspot virus type W (PRSV W). A, Plants of the transgenic line ZW-1 (right) did not show any symptoms after mechanical challenge with ZYMV (top row) or PRSV W (middle row), singly or together (ZYMV+PRSV W, bottom row); control mock-inoculated with buffer (NTMock; left). Scale bar at upper left of top row $=3.5 \mathrm{~cm}$. B, Panel I: $\mathrm{R}_{0}$ plant of transgenic line ZW-1 co-inoculated with ZYMV and PRSV W showing no symptoms. Panel II: nontransgenic plant inoculated with ZYMV showing yellow mosaic and mottling symptoms. Panel III: nontransgenic plants inoculated with PRSV W showing yellow mosaic and mottling symptoms. Panel IV: nontransgenic plant co-inoculated with ZYMV and PRSV W showing severe yellow mosaic symptoms with leaf distortion. Bar at upper left of panel I $=1 \mathrm{~cm}$. C, Graphic presentation of enzyme-linked immunosorbent assay results for detection of virus accumulation in susceptible ZW-23 transgenic melon line, immune ZW-1 line, and NT and NT-Mock negative control plants after mechanical inoculation with ZYMV and PRSV W singly or together.

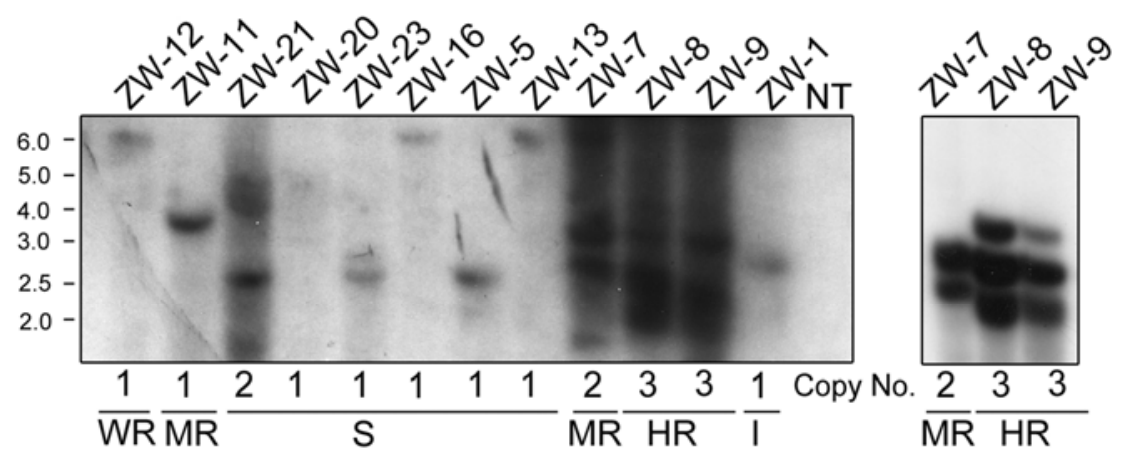

Fig. 4. Southern hybridization analyses of HindIII-restricted genomic DNA from the indicated transgenic lines using a radiolabeled probe of the partial Zucchini yellow mosaic virus (ZYMV) and Papaya ringspot virus type W (PRSV W) coat protein construct. Lanes are designated by name of specific transgenic line and from a nontransgenic (NT) control. Deduced transgene copy number and designated classification of transgenic lines based on level of virus resistance (S, WR, MR, HR, and I) are indicated at the bottom. Experiment with lines ZW-7, ZW-8, and ZW-9 was repeated for better clarity of signals (see inset at right). 
lum dosages, extent of wounding, physiological state, and age of transgenic seedlings or a chimeric nature of a transgenic line which may contain both transformed and untransformed cells. In order to minimize any variability caused by these factors, the challenge inoculation of transgenic plants was independently replicated for each line.

In general, the degree of RNA-mediated disease resistance of transgenic plants is correlated to the copy number of the transgene (39). However, the results of our Southern hybridization analysis of the present transgenic melon lines did not corroborate this notion. In particular, the immune line ZW-1 was found to carry a single copy of the transgene, as opposed to the susceptible lines ZW-21 and ZW-20, which carried several copies of the same. Since the highly resistant ZW-8 and ZW-9 lines showed similar Southern hybridization profiles, we cannot exclude the possibility that these two transgenic lines were actually developed from a single transformed cell.
Unlike in cucumber $(1,21,34)$ and watermelon (48), the genetics of natural resistance to ZYMV in melon is not fully understood, and there are discrepancies among the data from different groups. While the monogenic control of ZYMV resistance in melon (33) was supported by certain studies $(2,10)$, the investigation by Danin-Poleg et al. (9) provided convincing evidence for its oligogenic control. Anagostou et al. (2) attributed the discrepancies in the results of genetic analyses to the diversity of melon germplasm and variations in the virulence of ZYMV strains employed. Moreover, PRSV W resistance, a single gene trait $(32,46)$, and ZYMV resistance, possibly an oligogenic trait (9), are not genetically linked, and hence they tend to segregate independently (2). In the light of these facts, the present melon transformation is significant, since it links ZYMV and PRSV W resistances as a single (trans) gene trait and confers a high degree of resistance or immunity in melon to these two viruses.
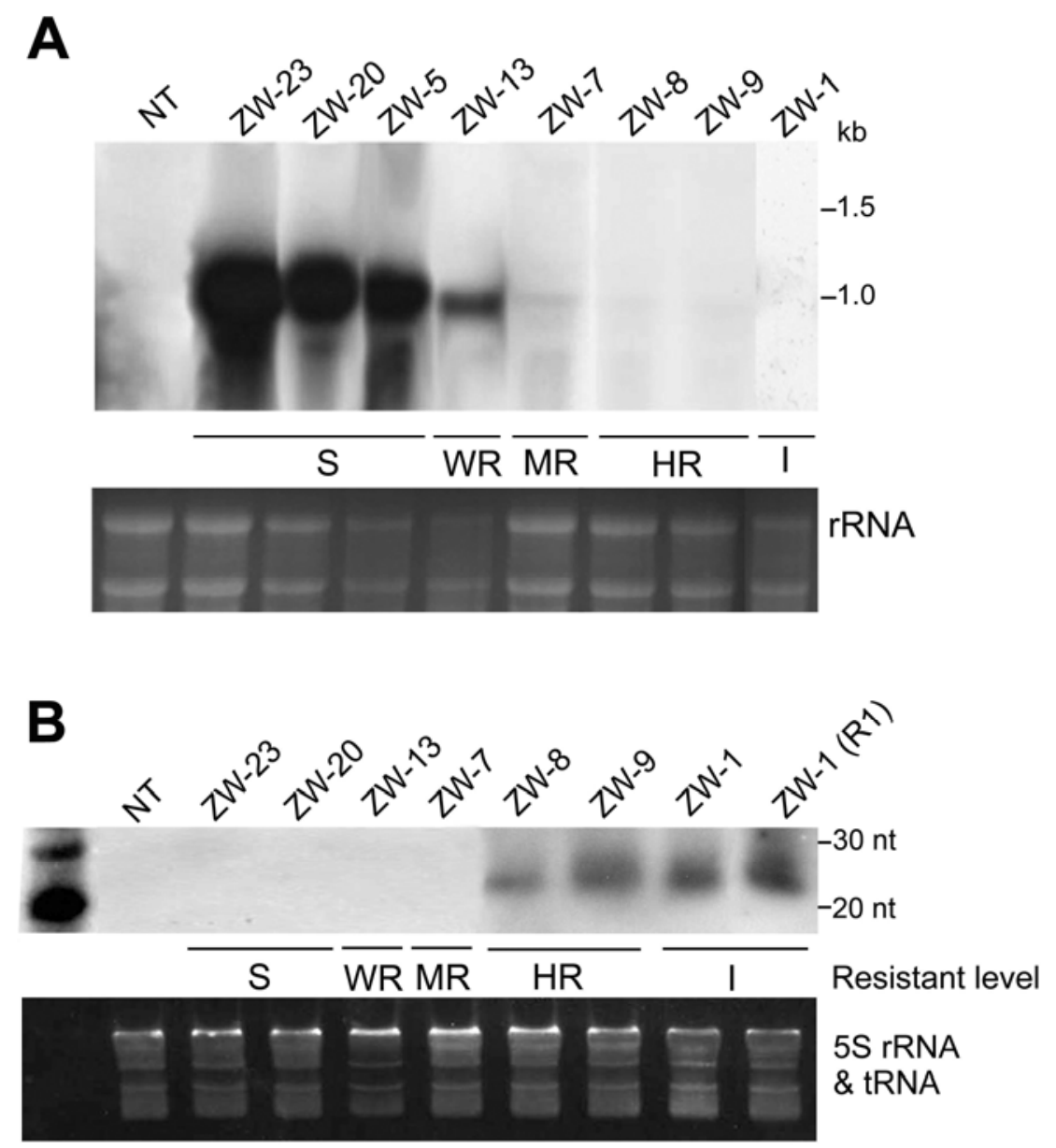

Fig. 5. Northern hybridization analysis with a ${ }^{32} \mathrm{P}$-radiolabeled probe to detect expression of the $\mathrm{ZW}$ transgene transcript and the accumulation of small interfering (si)RNA in the susceptible (S), resistant (R), highly resistant (HR), and immune (I) transgenic melon lines. A, Northern analysis of ZW coat protein (CP) transcript levels in the indicated transgenic melon plants and in a nontransgenic control (NT). Samples of ribosomal RNA were used as a loading control (lower panel). RNA sizes are indicated at right. B, Detection of siRNA specific to the $\mathrm{ZW} \mathrm{CP}$ transgene in the indicated transgenic melon lines and an NT control. The $\mathrm{R}_{1}$ progeny of immune line ZW-1 is indicated as ZW-1 (R1). Samples of 5S rRNA and tRNA were used as a loading control (lower panel). RNA sizes are indicated.

Our transgenic lines with high degrees of resistance or immunity against ZYMV and PRSV W have great potential for the control of the disease caused by these viruses in oriental melon in Asia and elsewhere. In the future, these transgenic ZYMV and PRSV W resistant and immune lines can be crossed with other elite transgenic melon cultivars resistant to other viruses for pyramiding multiple-virus resistance in melon.

\section{ACKNOWLEDGMENTS}

This study was supported by the National Agricultural Biotechnology Program (91AS-3.1-FD-Z3) from Council of Agriculture, Taiwan, R.O.C.

\section{LITERATURE CITED}

1. Abul, H. Z., and Al-Shahwan, I. 1991. Inheritance of resistance to Zucchini yellow mosaic virus in cucumber. J. Plant Dis. Prot. 98:301304.

2. Anagostou, K., Jahn, M., and Perl-Treves, R. 2000. Inheritance and linkage analysis of resistance to Zucchini yellow mosaic virus, Watermelon mosaic virus, Papaya ringspot virus and powdery mildew in melon. Euphytica 116:265270.

3. Baulcombe, D. 2004. RNA silencing in plants. Nature 431:356-363.

4. Bucher, E., Lohuis, D., van Poppel, P. M., Geerts-Dimitriadou, C., Goldbach, R., and Prins, M. 2006. Multiple virus resistance at a high frequency using a single transgene construct. J. Gen. Virol. 87:3697-3701.

5. Chang, Y. M., Hsaio, C. H., Yang, W. Z., Hseu, S. H., Chao, Y. J., and Huang, C. H. 1987. The occurrence and distribution of five cucurbit viruses on melon and watermelon in Taiwan. $\mathbf{J}$. Agric. Res. 36:389-397.

6. Chen, K. C., Chiang, C. H., Raja, J. A., Liu, F. L., Tai, C. H., and Yeh, S. D. 2008. A single amino acid of NIa-pro of Papaya ringspot virus determines host specificity for infection of papaya. Mol. Plant-Microbe Interact. 21:10461057.

7. Chen, T.-C., Lu, Y.-Y., Cheng, Y.-H., Chang, C.-A., and Yeh, S.-D. 2008. Melon yellow spo virus in watermelon: A first record from Taiwan. Plant Pathol. 57:765-765.

8. Cheng, Y. H., Liao, J. Y., Deng, T. C., Tasi, C H., and Hu, C. C. 2009. Prevalence of Squash leaf curl Philippines virus occurred on melon plants in south Taiwan. Plant Pathol. Bull 18:78.

9. Danin-Poleg, Y., Paris, H., Cohen, S., Rabinowitch, H., and Karchi, Z. 1997. Oligogenic inheritance of resistance to Zucchini yellow mosaic virus in melons. Euphytica 93:331-337.

10. Danin-Poleg, Y., Tadmor, Y., Tzuri, G., Reis, N., Hirschberg, J., and Katzir, N. 2002. Construction of a genetic map of melon with molecular markers and horticultural traits, and localization of genes associated with ZYMV resistance. Euphytica 125:373-384.

11. Desbiez, C., and Lecoq, H. 1997. Zucchini yellow mosaic virus. Plant Pathol. 46:809-829.

12. Fang, G., and Grumet, R. 1993. Genetic engineering of potyvirus resistance using constructs derived from the Zucchini yellow mosaic virus coat protein gene. Mol. PlantMicrobe Interact. 6:358-367.

13. Fuchs, M., and Gonsalves, D. 1995. Resistance of transgenic hybrid squash ZW-20 expressing the coat protein genes of Zucchini yellow mosaic virus and Watermelon mosaic virus 2 to mixed infections by both potyviruses. Bio/Technology 13:1466-1473.

14. Fuchs, M., McFerson, J., Tricoli, D., McMaster, J., Deng, R., Boeshore, M., Reynolds, J., Russell, P., Quemada, H., and Gonsalves, D. 
1997. Cantaloupe line CZW-30 containing coat protein genes of cucumber mosaic virus, Zucchini yellow mosaic virus, and Watermelon mosaic virus-2 is resistant to these three viruses in the field. Mol. Breed. 3:279-290.

15. Fuchs, M., Tricoli, D. M., Carney, K. J., Schesser, M., McFerson, J. R., and Gonsalves, D. 1998. Comparative virus resistance and fruit yield of transgenic squash with single and multiple coat protein genes. Plant Dis. 82:1350-1356.

16. Fulton, T. M. 1995. Microprep protocol for extraction of DNA from tomato and other herbaceous plants. Plant Mol. Biol. Rep. 13:207209.

17. Gaba, V., Zelcer, A., and Gal-On, A. 2004. Cucurbit biotechnology - The importance of virus resistance. In Vitro Cell. Dev. Biol., Plant 40:346-358.

18. Halliwell, R. S., Johnson, J., and Cotner, S. 1979. Watermelon mosaic virus disease of squash, watermelon and pumpkin. Misc. Publ., Texas Agric. Exp. Stn. 1435:1-5.

19. Huang, C. H., Liang, S. C., Deng, T. C., and Hseu, S. H. 1993. Comparison of diagnostic hosts and serological tests for four cucurbit potyvirus. Plant Pathol. Bull. 2:169-176.

20. Jan, F. J., Fagoaga, C., Pang, S. Z., and Gonsalves, D. 2000. A single chimeric transgene derived from two distinct viruses confers multi-virus resistance in transgenic plants through homology-dependent gene silencing. J. Gen. Virol. 81:2103-2109.

21. Kabelka, E., Ullah, Z., and Grumet, R. 1997. Multiple alleles for Zucchini yellow mosaic virus resistance at the zym locus in cucumber. Theor. Appl. Genet. 95:997-1104.

22. Krubphachaya, P., Juricek, M., and Kertbundit, S. 2007. Induction of RNA-mediated Resistance to Papaya ringspot virus Type W. J. Biochem. Mol. Biol. 40:404-411.

23. Lin, S. S., Hou, R. F., Huang, C. H., and Yeh, S. D. 1998. Characterization of Zucchini yellow mosaic virus (ZYMV) isolates collected from Taiwan by host reactions, serology, and RT-PCR. Plant Prot. Bull. 40:163-176.

24. Lin, S.-S., Wu, H.-W., Jan, F.-J., Hou, R. F., and Yeh, S.-D. 2007. Modifications of the helper component-protease of Zucchini yellow mosaic virus for generation of attenuated mutants for cross protection against severe infection. Phytopathology 97:287-296.

25. Lisa, V., Boccardo, G., D'Agostino, G., Dellavalle, G., and D'Aquilio, M. 1981. Characterization of a potyvirus that causes zucchini yellow mosaic. Phytopathology 71:667-672.

26. Mattanovich, D., Ruker, F., Machado, A.,
Laimer, M., Regner, F., Steinkellner, H., Himmler, G., and Katinger, H. 1989. Efficient transformation of Agrobacterium spp. by electroporation. Nucleic Acids Res. 17:6747.

27. Murashige, T., and Skoog, F. 1962. A revised medium for rapid growth and bioassays with tobacco tissue cultures. Physiol. Plant 15:473497.

28. Niu, Q. W., Lin, S. S., Reyes, J. L., Chen, K. C., Wu, H. W., Yeh, S. D., and Chua, N. H. 2006. Expression of artificial microRNAs in transgenic Arabidopsis thaliana confers virus resistance. Nature Biotechnol. 24:1420-1428.

29. Pang, S., Jan, F., Tricoli, D., Russell, P., Carney, K., Hu, J., Fuchs, M., Quemada, H., and Gonsalves, D. 2000. Resistance to Squash mosaic comovirus in transgenic squash plants expressing its coat protein genes. Mol. Breed. 6:87-93.

30. Park, S., Lee, J., Jegal, S., Jeon, B., Jung, M., Park, Y., Han, S., Shin, Y., Her, N., Lee, J., Lee, M., Ryu, K., Yang, S., and Harn, C. 2005. Transgenic watermelon rootstock resistant to CGMMV (Cucumber green mottle mosaic virus) infection. Plant Cell Rep. 24:350-356.

31. Pitrat, M., and Hammer, K. 2000. Some comments on infraspecific classification of cultivars of melon. Proc Cucurbitaceae 2000:29-36.

32. Pitrat, M., and Lecoq, H. 1983. Two alleles for Watermelon mosaic virus 1 resistance in melon. Cucurb. Genet. Coop. Rep. 6:52-53.

33. Pitrat, M., and Lecoq, H. 1984. Inheritance of Zucchini yellow mosaic virus resistance in $\mathrm{Cu}$ cumis melo L. Euphytica 33:57-61.

34. Provvidenti, R. 1987. Inheritance of resistance to a strain of Zucchini yellow mosaic virus in cucumber. Hortscience 22:102-103.

35. Provvidenti, R., Gonsalves, D., and Humaydan, H. S. 1984. Occurrence of Zucchini yellow mosaic virus in cucurbits from Connecticut, New York, Florida, and California. Plant Dis. 68:443-446.

36. Purcifull, D. E., Edwardson, J. R., Hiebert, E., and Gonsalves, D. 1984. Papaya ringspot virus. CMI/AAB Description of Plant Viruses No 292.

37. Sambrook, J., Fritsch, E., and Maniatis, T. 1989. Molecular Cloning: A Laboratory Manual, 2nd ed. Cold Spring Harbor Laboratory, New York.

38. Sanford, J. C., and Johnson, S. A. 1985. The concept of parasite-derived resistance: Deriving resistance genes from the parasites own genome. J. Theor. Biol. 115:395-405.

39. Sijen, T., Wellink, J. B., and van Kammen, A. 1996. RNA-mediated virus resistance: Role of repeated transgenes and delineation of targeted regions. Plant Cell 8:2277-2294.

40. Silberstein, L., Kovalski, I., Huang, R., Anagostou, K., Kyle Jahn, M., and Perl-Treves, R. 1999. Molecular variation in melon (Cucumis melo L.) as revealed by RFLP and RAPD markers. Sci. Hortic. 79:101-111.

41. Szittya, G., Silhavy, D., Molnár, A., Havelda, Z., Lovas, Á., Lakatos, L., Bánfalvi, Z., and Burgyán, J. 2003. Low temperature inhibits RNA silencing-mediated defence by the control of siRNA generation. EMBO J. 22:633 640.

42. Teixeira, A. P. M., and Camargo, L. E. A 2006. A molecular marker linked to the Prv ${ }^{1}$ gene that confers resistance to Papaya ringspot virus-type $\mathrm{W}$ in melon. Plant Breed. 125:187 190.

43. Trentini, L. 1998. Origine e botanica del melone. Suppl. l'inform. Agrar. 3:5-6.

44. Tricoli, D. M., Carney, K. J., Russell, P. F. McFerson, J. R., Groff, D. W., Hadden, K. C. Himmel, P. T., Hubbard, J. P., Boeshore, M. L. and Quemada, H. D. 1995. Field evaluation of transgenic squash containing single or multiple virus coat protein gene constructs for resistance to Cucumber mosaic virus, Watermelon mosaic virus 2, and Zucchini yellow mosaic virus. Bio/Technology 13:1458-1465.

45. Vaucheret, H., Beclin, C., Elmayan, T., Feuerbach, F., Godon, C., Morel, J. B., Mourrain, P. Palauqui, J. C., and Vernhettes, S. 1998 Transgenic-induced gene silencing in plant. Plant J. 16:651-659.

46. Webb, R. E. 1979. Inheritance of resistance to Watermelon mosaic virus in Cucumis melo $\mathrm{L}$. Hortscience 14:265-266

47. Wu, H.-W., Yu, T.-A., Raja, J. A. J., Wang, H. C., and Yeh, S.-D. 2009. Generation of transgenic oriental melon resistant to Zucchini yellow mosaic virus by an improved cotyledoncutting method. Plant Cell Rep. 28:1053-1064.

48. Xu, Y., Kang, D., Shi, Z., Shen, H., and Wehner, T. 2004. Inheritance of resistance to Zucchini yellow mosaic virus and Watermelon mosaic virus in watermelon. J. Hered. 95:498 502.

49. Yeh, S.-D., and Gonsalves, D. 1984. Purification and immunological analysis of cylindrical-inclusion protein induced by Papaya ringspot virus and Watermelon mosaic virus $\mathrm{I}$ Phytopathology 74:1273-1278.

50. Zhang, X., Yuan, Y.-R., Pei, Y., Lin, S.-S., Tuschl, T., Patel, D. J., and Chua, N.-H. 2006. Cucumber mosaic virus-encoded 2b suppressor inhibits Arabidopsis Argonaute1 cleavage activity to counter plant defense. Genes Dev. 20:3255-3268. 